\title{
Axillary Lymphadenopathy
}

National Cancer Institute

\section{Source}

National Cancer Institute. Axillary Lymphadenopathy. NCI Thesaurus. Code C35493.

A clinical finding indicating the enlargement of the lymph nodes in the axillary region. It

may be caused by infections, systemic diseases, or cancer. 